\title{
Evaluation of The Safety and Efficacy of Newly Developed Domestic Allergenic Extracts for Skin Prick Testing
}

\author{
Mohammad Fereidouni*1,2, Roya Mahdavi ${ }^{1}$, Sarah Mahmoudzade ${ }^{2}$, \\ Hadis Rezapoor $^{2}$, Alireza Fereidouni ${ }^{1}$, Afsane Bahrami ${ }^{1}$
}

\begin{abstract}
Background: Allergic disorders are common health problems worldwide with significant socio-economic impacts. The best diagnostic method using allergenic extract is the skin prick test. Regarding the effects of geo-climatic factors and allergenic extract source material quality, the aim of study was to determine the safety and efficacy of some in-house-developed allergenic extracts.

Methods: Forty-five different allergenic extracts, including common regional pollen, foods, and dog and cat hair, as well as positive and negative extracts, were prepared from domestic sources using optimum extraction methods. All extracts passed stability and sterility testing, and sterile final products containing $50 \%$ glycerin in 10 and $20 \mathrm{w} / \mathrm{v}$ concentrations were used. Skin prick testing was performed on volunteers and immediate or late side effects were recorded.

Results: In total, 56 students (mean age: $21.2 \pm 2.3 y, \mathrm{M} / \mathrm{F}$ ratio: 1.07) participated in this study. For inhalant allergens, all extracts except dog hair extract caused positive responses. Salsola kali (Russian thistle) and Fraxinus velutina (ash tree) were the most common grass and tree pollen extracts, respectively. Of 18 different food extracts, five, including egg white, tomato, fig, melon, and green pepper caused skin reactivity in only one person. No participant reported any immediate or late side effects, including large local reaction or systemic response.

Conclusions: The result of the current study confirmed the safety of all our in-house-developed allergenic extracts. Regarding efficacy, almost all inhalant and five food allergens caused positive skin responses.
\end{abstract}

Keywords: Allergenic extract, In-house extract, Skin prick test.

\section{Introduction}

The prevalence of allergic disorders, including allergic rhinitis (AR), asthma, and atopic dermatitis (AD), has been increasing in recent decades in many countries $(1,2)$. The prevalence of food allergies in children is $5 \%$ in Iran, and about $20-40 \%$ of the Iranian population suffers from AR. Epidemiological studies demonstrated that the distribution and pattern of allergen sensitivity are remarkably different between countries (3), and even in various parts of a country (4). Iran is a large country with different geo-climatic conditions and vegetation patterns, which can affect the type and amount of aeroallergens

Many studies have reported variations in sensitization patterns between allergic patients in different parts of the world $(5,6)$. Rather than genetic and individual factors, geoclimatic factors, particularly the plant vegetation pattern and abundance of specific plants in the area, influence the inhabitants' sensitization patterns $(5,7)$. 
Despite the prevalence and socio-economic burden of allergic disorders, the diagnostic methods for precise diagnosis of an allergy and identification of the causative agent are limited mostly to specific IgE detection (8) and skin prick testing (SPT). Skin prick testing is the most commonly accepted diagnostic method for confirming the presence of allergy to food or inhalant allergens (9). The SPT is simple, easy to perform, inexpensive, and safe (10), as the frequency of adverse events is very low (0.04\%) (10-12).

The differences between vegetation and allergic sensitization in each region (5-7), as well as the differences in potency and clinical validity of commercial allergen extracts, leads to the possibility that commercial extracts may not reflect the real exposure in various regions $(13,14)$. Identification of the potent local allergens in each area is important and emphasizes the diagnostic value of the skin prick test. In addition, the types and amounts of allergenic components in plants and food are affected by geo-climatic and cultivation factors (15-17); therefore, the extract source is important, and several countries have started producing domestic extracts from local resources $(18,19)$. Regarding the importance of allergenic extracts' quality and potency, and as the first step in producing domestic extracts in Iran, the aim of this study was to evaluate the safety and efficacy of 43 food and inhalant allergenic extracts prepared from domestic source material by the Sensitive Diagnostic Company of Iran.

\section{Materials and Methods Study Participants}

This study was performed in the immunology department of Birjand University of Medical Sciences (BUMS), Birjand, Iran. The study protocol was approved by the BUMS ethics committee (IR.bums.REC.1396.52). All the participants received detailed information about the study, and written informed consent was obtained from all of them. Fifty-six randomly selected medical students enrolled in the study voluntarily. Medical histories, including allergic disorders, drug use, and other health issues were obtained by a questionnaire. People with any serious diseases or drug use that might interfere with skin prick testing were omitted from the study.

\section{Skin prick test}

The skin prick test was performed according to the standard method in two consecutive weeks. In each week two dilutions (10 and $20 \mathrm{w} / \mathrm{v}$ ) of 43 allergenic extracts, including positive and negative controls, were tested by an expert allergist. The result of the skin test for each extract was read after 15 minutes and probable local and systemic side effects during 48 hours after the test were recorded.

\section{Preparation of Extracts}

Food extracts were prepared from fresh materials collected from different areas of the city at different times. For pollen-derived extracts, pollens were collected during two consecutive pollination seasons by vacuuming or water setting and then purified by serial sieving through micrometer meshes. The identity and purity of each lot of pollen was verified microscopically before extraction. In the case of cat and dog hair extracts, hair samples from several health-certified cats and dogs were collected and extracted by acetone precipitation. The schematic abstract of the extraction process is presented in Figure 1. For each allergen, 1/10 and 1/20 w/v dilutions were prepared and tested. Two histamine solutions (10 and $20 \mathrm{mg} / \mathrm{ml})$ and normal saline were used as positive and negative controls, respectively. All extracts had $50 \%$ of glycerol in their final form. For food extracts, $0.04 \%$ of phenol was added.

\section{Stability and Sterility Testing}

For stability testing, a final form of each extract was stored at $25{ }^{\circ} \mathrm{C}$ in an incubator for six months. After that, the total protein and profile of allergens were evaluated and compared to the fresh extracts. In case of any significant loss of activity, the extraction process was modified until optimum stability was achieved. All extracts were sterilized by filtration through 0.22-micron filters. For 
sterility testing, a sample of each extract was transferred to a nutrient agar plate and incubated for $48 \mathrm{~h}$ at $37^{\circ} \mathrm{C}$. If any bacterial growth was seen, the extract was discarded and a new extract was made.

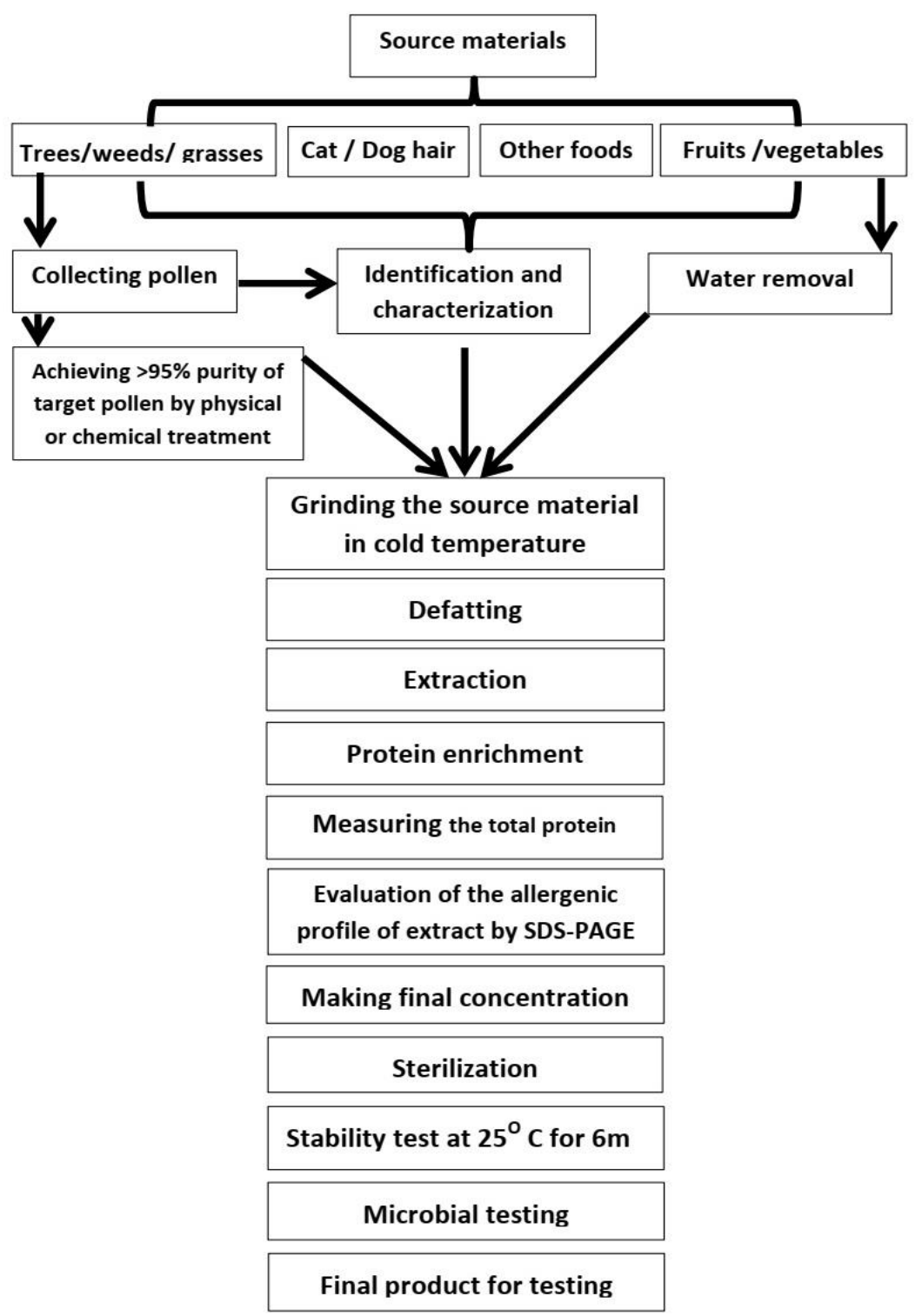

Fig. 1. Schematic of the allergen extraction process.

\section{Results}

In total, 56 student volunteers participated in this study. The participants' mean age was $21.2 \pm 2.3$ years, and 27 subjects $(48.2 \%)$ were female. For the positive and negative controls, $98.2 \%$ and $1.8 \%$ of the participants showed positive responses, respectively. The area of wheal created by $20 \mathrm{mg} / \mathrm{ml}$ of histamine was significantly larger than that caused by 10 $\mathrm{mg} / \mathrm{ml}$ of histamine $(35 \mathrm{~mm} 2$ vs $21 \mathrm{~mm} 2$; $\mathrm{P}<0.05)$. Figure 1 shows the skin reactivity to lower concentration of histamine and normal saline. For inhalant 2allergens, all extracts except dog hair extract caused a positive skin reaction at least in one person. In grass/weed extracts, Salsola kali (Russian thistle) showed the highest rate of sensitization and wheal size $42.8 \%$ and $39 \mathrm{~mm}^{2}$ ). For tree pollen extracts, Fraxinus velutina (ash tree) had the highest frequency $(14.5 \%)$. Figure 2 shows the percentage of skin reactivity and mean wheal area for inhalant allergenic extracts. Of 18 different food extracts, five, including egg 
white, tomato, fig, melon, and green pepper caused skin reactivity in just one person, but the rest were not reactive (Figure 3). Regarding side effects, except for the mild local itching and redness due to the positive skin reactions, no participant reported any immediate or late side effects, including large local reaction or systemic response.

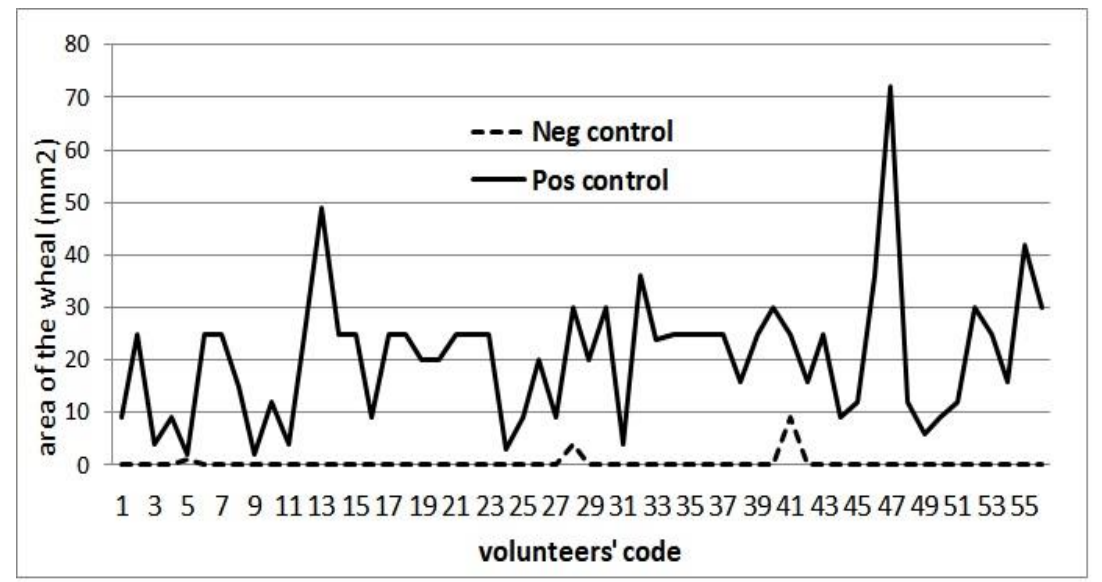

Fig. 1. Wheal areas caused by negative and positive control extracts in various individuals.

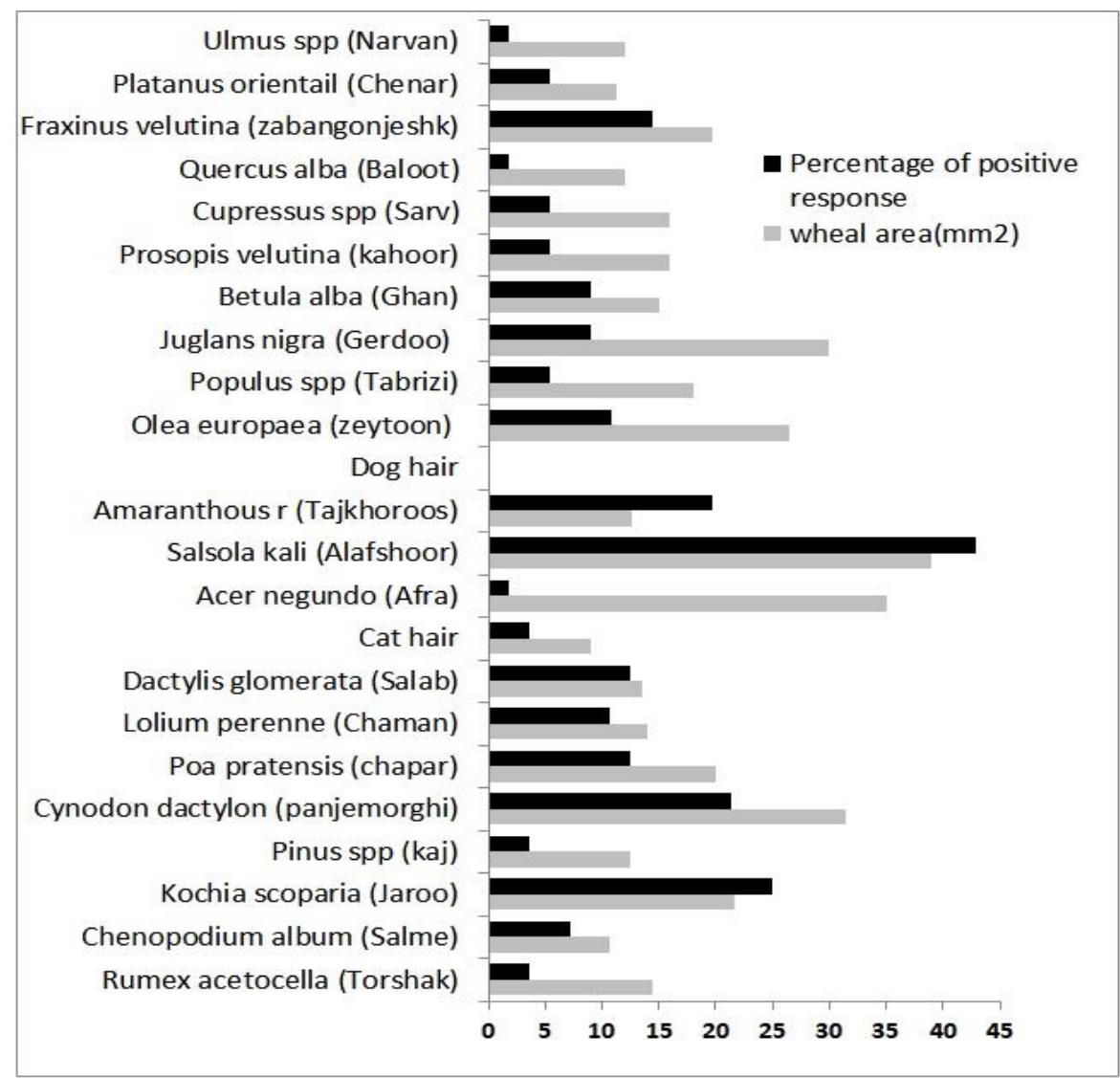

Fig. 2. Frequency of positive skin response and mean wheal sizes for various inhalant allergenic extracts (common Persian name). 


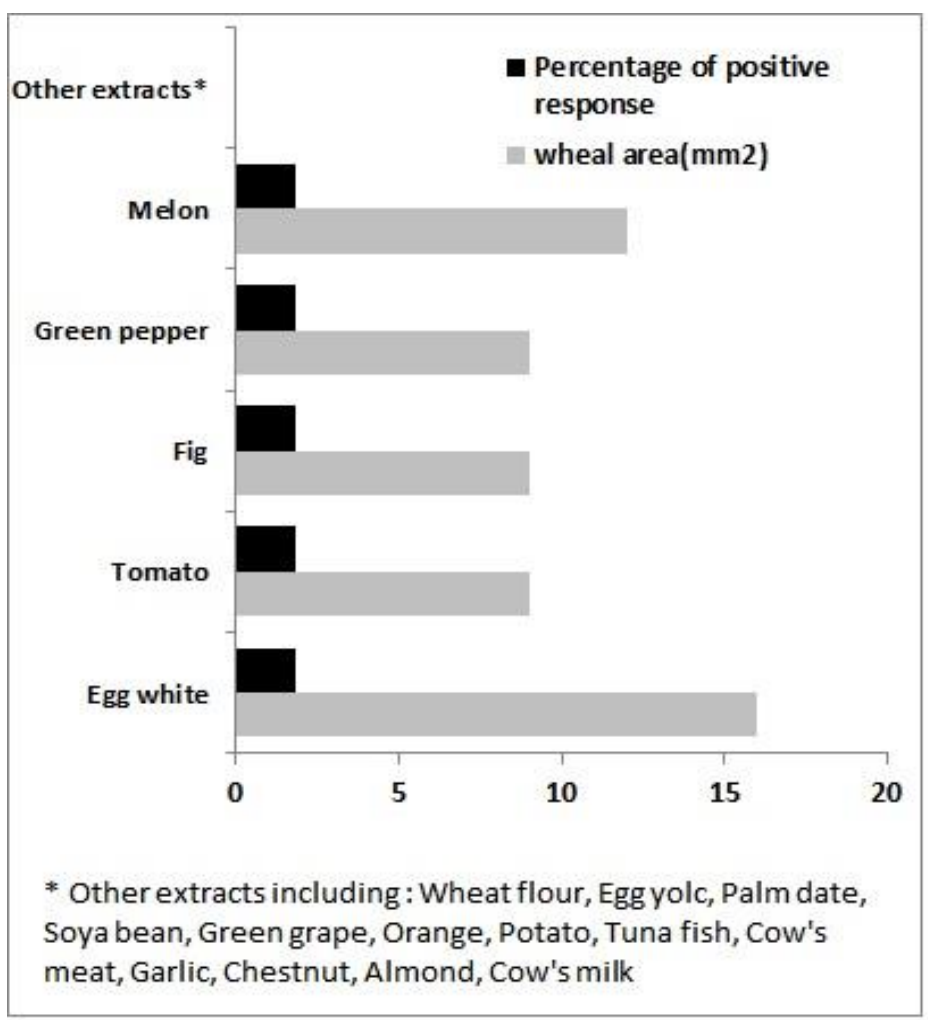

Fig. 3. Frequency of skin reactivity and mean wheal sizes for various food allergenic extracts.

\section{Discussion}

The skin prick test is a reliable diagnostic test for detecting allergens in allergic patients and is widely used in allergy clinics worldwide to identify the cause of allergic symptoms. The method is fast, simple, inexpensive, and educational, as the result is clear after 15 minutes. The main drawbacks are heterogeneity of commercial extracts and the source material, which can differ in each region (13-15).

In this study we evaluated the safety and potency of 43 newly developed domestic extracts. Regarding safety, no extract produced any immediate or delayed side effects, and all were well tolerated even at the higher concentration.

In concordance with our finding Lin et al. reported a $0.02 \%$ rate for systemic allergic reactions in SPT among more than 10,000 patients (20). Similarly, in a large retrospective study among four allergy services in Naples, Genoa, and Verona, of 55,105 patients who were tested for 684,306 allergens, only one systemic reaction was reported (12). In another survey, the risk of systemic reactions to SPT was estimated to be $0.005 \%$ in infants (21). A study conducted by Turkeltaub et al. on more than 16,000 cases reported the risk of SPT as low and similar to other routine medical procedures (11). In general, accumulating evidence indicated that the overall risk of severe reactions induced by SPT is very low, and this was confirmed in our study as well.

Histamine hydrochloride and 50\% glycerol saline should be used in any panel of SPT as positive and negative controls. The lower concentration positive control extract produced a reaction in all tested subjects, although in one participant the reaction intensity was less than expected, which could be due to drug use, SPT disturbance factors, or inadequate scratching during SPT. The negative control extract produced a 9 $\mathrm{mm}$ wheal in only one participant, which may have been due to sensitive skin, dermatographism, or deeper scratches (22). Parallel to our result several studies have shown the importance of technique, device, and operator on the test result, and reported false positive and false negative results (23-26). In addition, one study reported inter-individual and international variation in the rate of skin response to histamine (27).

Regarding the inhalant allergens, all extracts except dog hair created at least one positive 
response, and the rate of skin sensitivity was higher for weed and grass than for tree pollens. In concordance with our study, several studies in various parts of Iran, including Mashhad, Khoozestan, Kerman, Ahwaz, and Shiraz reported high skin sensitivity rates to grass and weed allergens, including Amaranthus Spp, Salsola kali, Kochia scoparia, and Chenopodium album (2832). Moghtaderi et al. reported the pollen sensitization rate at $74.5 \%$, which agreed with our results (33). A large variation in the rate of sensitivity to tree pollens was seen, possibly because of differences in the type and number of trees in each region, but most studies reported lower sensitization rates to tree than to grass and weed pollens. For example, in the Kerman study the rate of skin reaction to tree pollen was 2.5-9.6 percent among allergic patients (30), while in the Qazvin, Yasuj, and Ahwas the sensitivity rates among allergic patients were 26,18 , and $25-65 \%$, respectively $(34,35,31)$. Moghtaderi et al. also reported a lower prevalence of tree than grass pollen allergy in allergy patients (33).

Of the two animal hair allergens only cat hair extract caused positive responses. The rate of cat sensitization depends on exposure to cat allergens in the home or workplace (36). Keeping cats as pets is popular in Iranian families and feral cats are abundant in the streets. The sensitization rate to cat hair in allergic individuals varied from $13-23.5 \%$ in several reports from Iran (33-35), which is higher than our result, likely due to differences in the study populations. In a study from Shiraz, 7\% of the control group were sensitized to cat extract, which supports our finding (37). In contrast to cat, keeping dogs is condemned for religious or cultural reasons, thus the exposure to dog allergen is low. Several studies among allergic cases reported various sensitization rates to dog allergens, but generally the frequency is not high, particularly among non-atopic people $(34,37)$. As our study population was students who spend most of their times in dormitories and are not allowed to keep animals, the low sensitization rate was expected.

In the current study only five food extracts caused positive skin reactions. The overall prevalence of food allergies, particularly among adults, is very low. In a large survey among US adults the rate of self-reported food allergy was around $1 \%$ for most foods (38). Similarly in a European meta-analysis, the rate of positive skin test for food was $1.8-6.1 \%$ in teens. (39). In a systematic review including 36 studies and 250,000 children and adults, the rate of skin sensitization against any plant was less than $1 \%$ (40). Studies performed in Iran showed various food sensitization patterns, but consistent with our results, egg white, tomato, and pepper were among the most frequently seen food allergens (41-44). For example, in study performed by Ahanchian et al., egg white, pepper, and tomato were among the most common food allergens in children (45).

Several reasons can explain the low or zero prevalence of skin reactivity to some extracts. First, it could be due to extract quality, but as all the prepared extracts passed the stability test, and their allergenic profile was comparable to commercial extracts in SDS-PAGE, that possibility is unlikely. Second, and most likely, it could be because of our study population, which was a relatively small group of randomly selected adults regardless of their atopic status and not large enough to reveal the low-prevalence allergens. In this regard, the low or zero prevalence of skin reactivity to some extracts is expected and does not invalidate the efficacy of our extracts.

In conclusion, the result of the current study confirmed the safety of all in-house developed allergenic extracts. In the case of efficacy, almost all inhalant and five food allergens caused positive skin responses. After confirming the safety, a noninferiority study with matched commercial imported extracts will be performed to further assess the efficacy of our developed extracts.

\section{Acknowledgements}

This study was approved by the BUMS ethics committee (IR.bums.REC.1396.52) and supported by the Research Bice presidency of Birjand University of Medical Sciences and Sensitive Diagnostic Company (Hassas Tashkhis Gostar Khavaran, Co. Ltd., Birjand, Iran). The authors thank all the participants for their cooperation in this study. 


\section{References}

1. Zhang Y, Zhang L. Increasing prevalence of allergic rhinitis in China. Allergy Asthma Immunol Res. 2019;11(2):156-169.

2. Fereidouni M, Abolhasani A, Vahedi F, Shakeri MT, Varasteh A. A preliminary survey of the prevalence of allergic disorders in a questionnaire-based study in Boshroye, a rural area of Iran. Journal of Public Health. 2010;18:119-121.

3. Bousquet PJ, Chinn S, Janson C, Kogevinas M, Burney P, Jarvis D. Geographical variation in the prevalence of positive skin tests to environmental aeroallergens in the European Community Respiratory Health Survey I. Allergy. 2007;62(3):301-9.

4. Arnedo-Pena A, García-Marcos L, García GH, Aguinagua IO, González CD, Morales MS$\mathrm{V}$, et al. Time trends and geographical variations in the prevalence of symptoms of allergic rhinitis in 6-7-year-old children from eight areas of Spain according to the ISAAC. An Pediatr (Barc). 2005;62(3):229-36.

5. Greiner AN, Hellings, PW, Rotiroti G, Scadding, GK. Allergic rhinitis. Lancet. 2011;378(9809):2112-22.

6. Larenas-Linnemann DE, Fogelbach GA, Alatorre AM, Cruz AA, Colin DD, Pech JA, et al. Patterns of skin prick test positivity in allergic patients: usefulness of a nationwide SPT chart review. Allergol Immunopathol (Madr). 2011;39(6):330-6.

7. Larenas-Linnemann D, Michels A, Dinger H, Shah-Hosseini K, Mosges R, Arias-Cruz A, et al. Allergen sensitization linked to climate and age, not to intermittent-persistent rhinitis in a crosssectional cohort study in the (sub)tropics. Clin Transl Allergy. 2014;4:20.

8. Savi E, Peveri S, Cavaliere C, Masieri S, Montagni M. Laboratory tests for allergy diagnosis. J Biol Regul Homeost Agents. 2018;32(1 Suppl. 1):25-28.

9. Heinzerling L, Mari A, Bergmann KC, Bresciani M, Burbach G, Darsow U, et al. The skin prick test - European standards. Clin Transl Allergy. 2013;3(1):3.

10. Reid MJ, Lockey RF, Turkeltaub PC, PlattsMills TA. Survey of fatalities from skin testing and immunotherapy 1985-1989. J Allergy Clin Immunol. 1993;92(1 Pt 1):6-15.

11. Turkeltaub PC, Gergen PJ. The risk of adverse reactions from percutaneous prickpuncture allergen skin testing, venipuncture, and body measurements: data from the Second National Health and Nutrition Examination Survey 1976-1980 (NHANES II). Journal of allergy and clinical immunology. 1989;84(6):886-890.

12. Codreanu F, Moneret-Vautrin D, Morisset M, Guénard L, Rancé F, Kanny G, et al. The risk of systemic reactions to skin prick-tests using food allergens: CICBAA data and literature review. Eur Ann Allergy Clin Immunol. 2006;38(2):52-4.

13. Focke M, Marth K, Flicker S, Valenta R. Heterogeneity of commercial timothy grass pollen extracts. Clin Exp Allergy. 2008;38(8):1400-8.

14. Nielsen NH, Dirksen A, Mosbech H, Launbjerg J, Biering I, Soborg M. Skin prick testing with standardized extracts from 3 different manufacturers. A comparative randomized study. Allergol Immunopathol (Madr). 1992;20(6):246-8.

15. Bijli KM, Singh BP, Sridhara S, Gaur SN, Arora N. Standardizing Imperata cylindrica-source material for quality allergen preparations. J Immunol Methods. 2002;260(1-2):91-6.

16. Esch RE. Allergen source materials: state-ofthe-art. Arb Paul Ehrlich Inst Bundesinstitut Impfstoffe Biomed Arzneim Langen Hess. 2009;96:5-11: discussion 11.

17. Codina R, Crenshaw RC, Lockey RF. Considerations About Pollen Used for the Production of Allergen Extracts. J Allergy Clin Immunol Pract. 2015;3(5):676-82.

18. Lee SC, Sim DW, Lee J, Jeong KY, Park $\mathrm{KH}$, Lee JH, et al. Comparison between Newly Developed and Commercial Inhalant Skin Prick Test Reagents Using In Vivo and In Vitro Methods. J Korean Med Sci. 2018;33(13):e101. 19. Visitsunthorn N, Visitsuntho K, Pacharn P, Jirapongsananuruk O, Bunnag C. Comparison of the efficacy and safety of pollen allergen extracts using skin prick testing and serum specific $\operatorname{IgE}$ as 
references. Asian Pac J Allergy Immunol. 2017;35(4):191-195.

20. Lin MS, Tanner E, Lynn J, Friday JG.

Nonfatal systemic allergic reactions induced by skin testing and immunotherapy. Ann Allergy. 1993;71(6):557-62.

21. Devenney I, Fälth-Magnusson K. Skin prick tests may give generalized allergic reactions in infants. Ann Allergy Asthma Immunol. 2000;85(6 Pt 1):457-60.

22. Norrman G, Fälth-Magnusson K. Adverse reactions to skin prick testing in childrenprevalence and possible risk factors. Pediatr Allergy Immunol. 2009;20(3):273-8.

23. Dykewicz MS, Lemmon JK, Keaney DL. Comparison of the Multi-Test II and Skintestor Omni allergy skin test devices. Ann Allergy Asthma Immunol. 2007;98(6):559-62.

24. Engler D. Device Technique Used in Skin Test Study. J Allergy Clin Immunol Pract. 2016;4(4):791.

25. Buyuktiryaki B, Sahiner UM, Karabulut E, Cavkaytar O, Tuncer A, Sekerel BE. Optimizing the use of a skin prick test device on children. Int Arch Allergy Immunol. 2013;162(1):65-70.

26. Werther RL, Choo S, Lee KJ, Poole D, Allen KJ, Tang ML. Variability in skin prick test results performed by multiple operators depends on the device used. World Allergy Organ J. 2012;5(12):200-4.

27. Ronchetti R, Villa MP, Bohmerova Z, Martella S, Falasca C, Barreto M, et al. Skin reactivity to histamine and codeine in unselected 9-year-old children from Italy, Poland and Libya. Int Arch Allergy Immunol. 2004;135(2):136-42.

28. Fereidouni M, Hossini RF, Azad FJ, Assarezadegan MA, Varasteh A. Skin prick test reactivity to common aeroallergens among allergic rhinitis patients in Iran. Allergol Immunopathol (Madr). 2009;37(2):73-9.

29. Zare Marzouni H, Akrami R, Shalilian M, Kalani N, Noori Ahmad Abadi M, Kooti W. Investigating the Prevalence, Determining the Effects of Immunologic Sensitization and Clinical Symptoms Related to Allergens Existing in Khuzestan Province. Journal of Fasa University of Medical Sciences. 2016;6(1):96-105.

30. Fouladseresht H, Safiri S, Moqaddasi M, Razeghi M S, Bazargan N. Prevalence of food and airborne allergens in allergic patients in Kerman, . Journal of Kermanshah University of Medical Sciences. 2014;18(4):e74114.

31. Assarehzadegan MA, Shakurnia A, Amini A. The most common aeroallergens in a tropical region in Southwestern Iran. World Allergy Organ J. 2013;6(1):7.

32. Moghtaderi M, Hejrati Z, Kolahi N, Heidari B. Sensitization to aeroallergens in patients with allergic rhinitis, asthma, and atopic dermatitis in Shiraz, Southwestern Iran. Indian Journal of Allergy, Asthma and Immunology. 2015;29(2):79-83.

33. Moghtaderi M, Hejrati Z, Kolahi N, Heidari B. Sensitization to aeroallergens in patients with allergic rhinitis, asthma, and atopic dermatitis in Shiraz, Southwestern Iran. Indian Journal of Allergy, Asthma and Immunology. 2015;29(2):79.

34. Shokouhi Shoormasti R, Sabetkish N, Kazemnejad A, Vahabi N, Fazlollahi MR, Pourpak Z. Are the most common food allergens in an Iranian atopic population compatible with worldwide reports? A systemic review and metaanalysis with molecular classification of frequent allergens. Allergologia et Immunopathologia. 2019;47(6):604-618.

35. Manuchehr Mahram AB, Negin Nejatian. The Frequency of Common Allergens in Allergic Rhinitis among the Patients Referred to the Allergy Clinic of Qods Hospital in Qazvin during 2007-2010. Journal of Allergy \& Therapy. 2013;4(1).

36. Chapman MD, Wood RA. The role and remediation of animal allergens in allergic diseases. J Allergy Clin Immunol. 2001;107(3 Suppl):S414-21.

37. Moghtaderi M, Farjadian S, Hosseini Z, Eghtedari D. The comparison of sensitization to animal allergens in children and adult-onset patients with asthma. Indian Journal of Allergy, Asthma and Immunology. 2015;29(2):67-71.

38. Gupta RS, Warren CM, Smith BM, Jiang J, Blumenstock JA, Davis MM, et al. Prevalence and Severity of Food Allergies Among US Adults. JAMA Netw Open. 2019;2(1):e185630. 39. Nwaru B, Hickstein L, Panesar S, Muraro A, Werfel T, Cardona V, et al. The epidemiology of food allergy in Europe: A 
systematic review and meta-analysis. Allergy. 2014;69(1):62-75.

40. Zuidmeer L, Goldhahn K, Rona RJ, Gislason D, Madsen C, Summers C, et al. The prevalence of plant food allergies: a systematic review. J Allergy Clin Immunol. 2008;121(5):1210-8.e4. 41. Farjadian S, Moghtaderi M, Kashef S, Alyasin S. Sensitization to food allergens in Iranian children with mild to moderate persistent asthma. World J Pediatr. 2012;8(4):317-20.

42. Hosseini S, Shoormasti RS, Akramian R, Movahedi M, Gharagozlou M, Foroughi N, et al. Skin prick test reactivity to common aero and food allergens among children with allergy. Iran J Med Sci. 2014;39(1):29-35.
43. Moghtaderi M, Farjadian S, Kashef S, Alyasin S, Afrasiabi M, Orooj M. Specific IgE to common food allergens in children with atopic dermatitis. Iran $\mathbf{J}$ Immunol. 2012;9(1):32-8.

44. Salehi T, Pourpak Z, Karkon S, Shoormasti RS, Sabzevari SK, Movahedi $M$, et al. The study of egg allergy in children with atopic dermatitis. World Allergy Organ J. 2009;2(7):123-127.

45. Ahanchian $\mathrm{H}$, Jafari S, Behmanesh $\mathrm{F}$, Haghi NM, Nakhaei AA, Kiani MA, et al. Epidemiological survey of pediatric food allergy in Mashhad in Northeast Iran. Electronic physician. 2016;8(1):1727-1732. 